\title{
Single Electron Transfer (SET) Pathway: Nucleophilic Substitution Reaction of 4-Chloro-7-nitrobenzofurazan with Anilines in MeOH-MeCN Mixtures
}

\author{
Hojune Choi, Kiyull Yang, ${ }^{*}$ Sang-Gyeong Lee, ${ }^{\dagger}$ Jong Pal Lee,, and In Sun Koo* $^{*}$ \\ Department of Chemistry Education and Research Institute of Natural Science, Gyeongsang National University, \\ Jinju 660-701, Korea. E-mail: iskoo@gnu.ac.kr \\ 'Department of Chemistry and Research Institute of Natural Science, Gyeongsang National University, Jinju 660-701, Korea \\ ${ }^{\ddagger}$ Department of Chemistry, Dong-A University, Pusan 604-714, Korea \\ Received August 19, 2010, Accepted August 28, 2010
}

\begin{abstract}
A nucleophilic substitution reaction of 4-chloro-7-nitrobenzofurazan (NBF-Cl) with anilines in MeOH-MeCN mixtures was conducted at 25,35 , and $45^{\circ} \mathrm{C}$. Based on the higher $\beta_{\text {nuc }}$ values $(1.0-1.6)$ of the reaction and a good correlation of the rate constants with the reduction potentials of the aniline nucleophiles, the present reaction was initiated by a single electron transfer (SET). After this step, the reaction proceeds through a transition state similar to the normal $\mathrm{S}_{\mathrm{N}} \mathrm{Ar}-\mathrm{Ad}$.E pathway.
\end{abstract}

Key Words: Single electron transfer (SET) pathway, $\mathrm{S}_{\mathrm{N}} \mathrm{Ar}-\mathrm{Ad}$.E mechanism, Structure-reactivity correlations, Hydrogen bond, Isodielectric solvents

\section{Introduction}

Nucleophilic aromatic substitution reactions are thought to involve four possible mechanisms: (i) bimolecular nucleophilic aromatic substitution, $\mathrm{S}_{\mathrm{N}} \mathrm{Ar}$-Ad.E (addition-elimination pathway) ${ }^{1}$ (ii) an elimination-addition process, $\mathrm{S}_{\mathrm{N}} \mathrm{Ar}$-E.Ad or $\mathrm{S}_{\mathrm{N}} 1 \mathrm{Ar}$ (similar to a $\mathrm{S}_{\mathrm{N}} 1$ mechanism); ${ }^{1,2}$ (iii) bimolecular concerted aromatic nucleophilic substitution, $\mathrm{S}_{\mathrm{N}} 2 \mathrm{Ar}$ ( similar to a $\mathrm{S}_{\mathrm{N}} 2$ mechanism); ${ }^{1}$ and (iv) a single electron transfer (SET) pathway. ${ }^{3-5}$ In the SET mechanism, the reaction accompanies the formation of a $\sigma$-complex intermediate through an initial single electron transfer from a nucleophilic amine donor to an aromatic acceptor moiety having strong electron withdrawing substituents. ${ }^{3-5}$ The nucleophilic aromatic substitution reaction of the aromatic compounds with amines generally involves the $\mathrm{S}_{\mathrm{N}}$ Ar-Ad.E mechanism (eq. 1). ${ }^{6,7}$ However, the nucleophilic aromatic substitution reaction with high $\beta_{\text {nuc }}(>1.0)$ values involves the formation of an intermediate through the initial SET pathway. ${ }^{3-5}$ The significance of structure-reactivity relationships such as Hammett $\rho$, Brønsted $\beta$ coefficients, and crossinteraction constants $\rho_{\mathrm{ij}}$ as a mechanistic criterion for nucleophilic substitution or addition reactions as well as in the proton transfer process has been discussed by Jenks, ${ }^{8}$ Terrier, ${ }^{9}$ and Lee. ${ }^{9,10}$ The $\beta_{\text {nuc }}$ values are commonly accepted as measures of the degree of charge transfer from a base to an acid partner in the transition state (TS). ${ }^{8,11}$ However, as pointed out by Bordwell and others, such $\beta_{\text {nuc }}$ values indicate the degree of bond formation in the rate-determining TS of $\mathrm{S}_{\mathrm{N}} \mathrm{Ar}-\mathrm{Ad}$.E and $\mathrm{S}_{\mathrm{N}} 2$ reactions. ${ }^{12}$ The normal range of $\beta_{\text {nuc }}$ values would be between 0 and $1 .{ }^{9}$ However, in previous works $\beta_{\text {nuc }}$ values outside the normal range have often been observed. ${ }^{9,13-15}$ In particular, a nucleophilic aromatic substitution reaction with high $\beta_{\text {nuc }}$ values proceeds through the SET pathway rather than the normal $\mathrm{S}_{\mathrm{N}} \mathrm{Ar}$-Ad.E mechanism.

Many researchers are interested in the nature of specific solvent effects on nucleophilic aromatic substitution in isodielectric solvents such as methanol-acetonitrile mixtures. ${ }^{16,17}$ Rates of reactions between polar molecules are quite insensitive to change from a dipolar aprotic to a protic solvent of the same dielectric constant when there exists only electrostatic interactions between reactants (or TS) and solvents. ${ }^{16,17}$ However, when specific solvation occurs between them, the rate is remarkably changed in isodielectric solvents such as methanol-acetonitrile mixtures. $^{16,18}$

The reaction mechanism, reactivity, and solvents effects in these systems have been examined extensively, ${ }^{19-21}$ and we have recently studied the nucleophilic displacement reaction of strongly activated chlorinated aromatic compounds in methanol-acetonitrile solvents. ${ }^{22}$ It was assumed that electrophilic catalysis by methanol occurred, likely as a result of hydrogen bonding between alcoholic hydrogen, leaving chloride in the $\mathrm{TS}^{22}$ Therefore, mechanistic study on the nucleophilic substitution reaction between aromatic compounds having strong electron withdrawing substituents and amines is very important in examining the effects of protic solvents in the ground state (GS) or TS (or intermediate). In this work, we determined the second-order rate constants for the reaction of 4- chloro-7-nitrobenzofurazan (NBF-Cl, eq. 1) with anilines in $\mathrm{MeOH}-\mathrm{MeCN}$ mixtures at 25,35 , and $45^{\circ} \mathrm{C}$. In order to discuss the reaction mechanism and solvent effects, we determined transition state parameters, $\rho_{\mathrm{N}}$ and $\beta_{\text {nuc, }}$ using Hammett and simple Brönsted relationships, reduction potential $\left(E^{\circ}\right)$ of amines, and activation parameters.

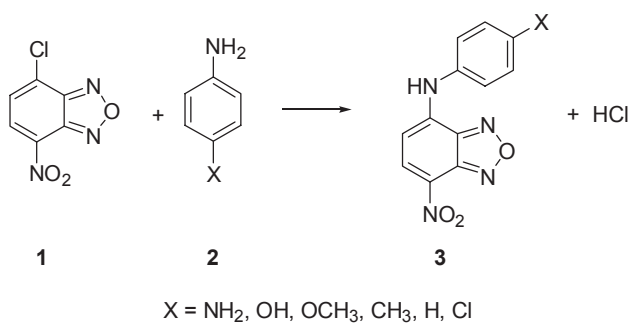




\section{Results and Discussion}

The present reactions obey the kinetic law given in eq. 2 . Plots of pseudo-first-order rate constants $k_{\text {obs }}$ against [anilines] show a good linear relationship, as shown in Figure 1. The second-order rate constants $k_{2}$, were determined from the slopes of these plots and are summarized in Table 1. No third-order or higher-order terms were detected, and no complication was encountered in the determination of $k_{\text {obs }}$ or in the linear plots of eq. (1b). This suggests that neither base-catalysis nor noticeable side reactions take place, and the overall reaction follows the route given by eq. $1 .^{21}$

$$
\text { Rate } \left.\left.=k_{2} \text { [anilines }\right][\text { substrates }]=k_{\text {obs }} \text { [substrates }\right]
$$

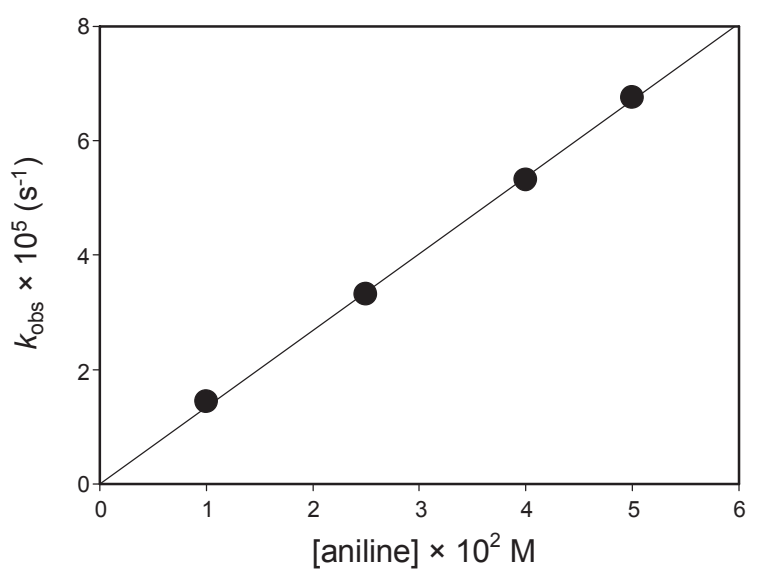

Figure 1. A plot of the observed first-order rate constant $\left(k_{\mathrm{obs}} \times 10^{5} \mathrm{~s}^{-1}\right)$ against concentration of aniline for the reaction of 4-chloro-7-nitrobenzofurazan with aniline in $50 \% \mathrm{MeCN}-50 \% \mathrm{MeOH}$ solvents at $35^{\circ} \mathrm{C}\left(k_{2}=1.32 \times 10^{-3} \mathrm{M}^{-1} \mathrm{~s}^{-1}\right)$.

Table 1. The second-order rate constants $\left(k_{2} \times 10^{3}\right)$ for the reaction of 4-chloro-7-nitrobenzofurazan with 4-X-anilines in $\mathrm{MeCN}-\mathrm{MeOH}$ mixtures

\begin{tabular}{|c|c|c|c|}
\hline & $\mathrm{p} K_{\mathrm{a}}$ & Solvent (v/v) & $k_{2} \times 10^{3}\left(\mathrm{M}^{-1} \mathrm{~s}^{-1}\right)$ \\
\hline \multirow[t]{3}{*}{$4-\mathrm{Cl}$} & 3.81 & $\mathrm{MeOH}$ & $0.723(r=0.998)$ \\
\hline & & $50 \% \mathrm{MeCN}-50 \% \mathrm{MeOH}$ & $0.151(\mathrm{r}=0.999)$ \\
\hline & & $\mathrm{MeCN}$ & $0.0117(\mathrm{r}=0.999)$ \\
\hline \multirow[t]{3}{*}{$\mathrm{H}$} & 4.58 & $\mathrm{MeOH}$ & $2.67(\mathrm{r}=0.999)$ \\
\hline & & $50 \% \mathrm{MeCN}-50 \% \mathrm{MeOH}$ & $0.851(r=0.981)$ \\
\hline & & $\mathrm{MeCN}$ & $0.0687(\mathrm{r}=0.999)$ \\
\hline \multirow[t]{3}{*}{$4-\mathrm{CH}_{3}$} & 5.07 & $\mathrm{MeOH}$ & $9.59(\mathrm{r}=0.984)$ \\
\hline & & $50 \% \mathrm{MeCN}-50 \% \mathrm{MeOH}$ & $6.35(\mathrm{r}=0.981)$ \\
\hline & & $\mathrm{MeCN}$ & $0.351(\mathrm{r}=0.997)$ \\
\hline \multirow[t]{3}{*}{$4-\mathrm{OCH}_{3}$} & 5.29 & $\mathrm{MeOH}$ & $29.3(r=0.995)$ \\
\hline & & $50 \% \mathrm{MeCN}-50 \% \mathrm{MeOH}$ & $16.8(\mathrm{r}=0.999)$ \\
\hline & & $\mathrm{MeCN}$ & $1.59(r=0.996)$ \\
\hline \multirow[t]{2}{*}{$4-\mathrm{OH}$} & 5.50 & $\mathrm{MeOH}$ & $57.1(\mathrm{r}=0.999)$ \\
\hline & & $50 \% \mathrm{MeCN}-50 \% \mathrm{MeOH}$ & $26.6(r=0.999)$ \\
\hline \multirow[t]{3}{*}{$4-\mathrm{NH}_{2}$} & 6.08 & $\mathrm{MeOH}$ & $149(\mathrm{r}=0.999)$ \\
\hline & & $50 \% \mathrm{MeCN}-50 \% \mathrm{MeOH}$ & $140(r=0.999)$ \\
\hline & & $\mathrm{MeCN}$ & $49.9(\mathrm{r}=0.999)$ \\
\hline
\end{tabular}

$$
k_{\mathrm{obs}}=k_{2} \text { [anilines] }
$$

Solvent effects. Table 1 shows that the second-order rate constant $\left(k_{2}\right)$ for the reaction of NBD-Cl with anilines increases as the methanol volume percent rises, i.e., increases from $1.17 \times$ $10^{-5} \mathrm{M}^{-1} \mathrm{~s}^{-1}$ in acetonitrile to $72.3 \times 10^{-5} \mathrm{M}^{-1} \mathrm{~s}^{-1}$ in methanol for $p$-chloroaniline nucleophile. Converse results are obtained for the reaction of 4-substituted-2,6-dinitrochloro benzenes with pyridines $^{12(\mathrm{c})}$ and benzylamines ${ }^{23}$ in $\mathrm{MeOH}-\mathrm{MeCN}$ mixtures at $25^{\circ} \mathrm{C}$. It is noted that the solvation effect on TS or intermediate by methanol is more important than the hydrogen bonded effect on aniline by methanol in GS. However, hydrogen bonded pyridines and benzylamines by methanol are less reactive than free pyridine and benzylamine in acetonitrile solvent: attacking pyridine is a weak nucleophile in methanol, but becomes more reactive in acetonitrile. ${ }^{12(c)}$ The increases in the second-order rate constant $\left(k_{2}\right)$ by increasing the volume percent of methanol indicate that the stabilization of the TS or Meisenheimer $\sigma$ complex due to the hydrogen bond with methanol is greater than stabilization of ground state (GS). The specific rate ratio, $k_{\mathrm{MeOH}} / k_{\mathrm{MeCN}}$, varied significantly over the full range of 4-substituted aniline nuclophiles. The ratios decrease from 61.8 to $38.8,27.3,18.4$, and 2.98 as the $\mathrm{p} K_{\mathrm{a}}$ values of anilines increase from 3.83 (for 4-Cl) to 4.58 (for 4-H), 5.07 (for 4- $\mathrm{CH}_{3}$ ), 5.29 (for 4-OCH 3 ), and 6.08(for 4- $\mathrm{NH}_{2}$ ), respectively. This may be attributed to the reduced nucleophilicity of anilines in methanol solvent, which stems from enhanced hydrogen bonding ability between aniline and methanol at higher $\mathrm{p} K_{\mathrm{a}}$ values.

Structure-reactivity comelations. Table 1 shows that the rate constant increases in the order of $\mathrm{X}=4-\mathrm{Cl}<\mathrm{H}<4-\mathrm{CH}_{3}<$ $4-\mathrm{OCH}_{3}<4-\mathrm{OH}<4-\mathrm{NH}_{2}$, where $\mathrm{X}$ is aniline substituents. The $\beta_{\text {nuc }}$ values were determined by plotting $\log k_{2}(\mathrm{MeCN}-\mathrm{MeOH})$ against $\mathrm{p} K_{\mathrm{a}}\left(\mathrm{H}_{2} \mathrm{O}\right)$ of anilines. ${ }^{24,25}$ Both the Hammett and Brönsted plots show good linearity, as presented in Figures 2 and 3. The transition parameters, Hammett $\rho_{\mathrm{N}}$ values, and Brönsted $\beta_{\text {nuc }}$ values are summarized in Table 2 . The $\rho_{\mathrm{N}}$ values are -2.70 , -3.45 , and -4.17 in $\mathrm{MeOH}, 50 \% \mathrm{MeOH}-50 \% \mathrm{MeCN}$, and $\mathrm{MeCN}$, respectively (Table 2). These results are comparable with the values of -3.70 reported by Ryan for substitutions of picryl chloride by a similar set of anilines in a $75-25(\mathrm{v} / \mathrm{v})$ EtOH- $\mathrm{H}_{2} \mathrm{O}$ mixture, ${ }^{26}$ and are also similar to the results for the substitution reaction of 4-X-2,5-dinitrochlorobenzene with anilines, benzylamines, and pyridines in $\mathrm{MeOH}-\mathrm{MeCN}(\mathrm{v} / \mathrm{v}$ ) mixtures. $^{12(\mathrm{c}), 23,27}$ The $\beta_{\text {nuc }}$ values are $1.08,1.36$, and 1.62 in $\mathrm{MeOH}$, $50 \% \mathrm{MeOH}-50 \% \mathrm{MeCN}$, and $\mathrm{MeCN}$, respectively (Table 2). The large negative $\rho_{\mathrm{N}}$ and large positive $\beta_{\text {nuc }}$ values obtained in the present work are consistent with significant development of a positive charge at the nitrogen atom of the aniline moiety and the negative charge developed in the substrate aromatic

Table 2. Hammett $\rho_{\mathrm{N}}$ values and Brönsted $\beta_{\text {nuc }}$ values for the reaction of 4-chloro-7-nitrobenzofurazan with 4-X-anilines in $\mathrm{MeOH}-\mathrm{MeCN}$ mixtures at $25{ }^{\circ} \mathrm{C}$

\begin{tabular}{ccc}
\hline Solvent $(\mathrm{v} / \mathrm{v})$ & $\rho_{\mathrm{N}}$ & $\beta_{\text {nuc }}$ \\
\hline $\mathrm{MeOH}$ & -2.70 & 1.08 \\
$50 \% \mathrm{MeCN}-50 \% \mathrm{MeOH}$ & -3.45 & 1.36 \\
$\mathrm{MeCN}$ & -4.17 & 1.62 \\
\hline
\end{tabular}




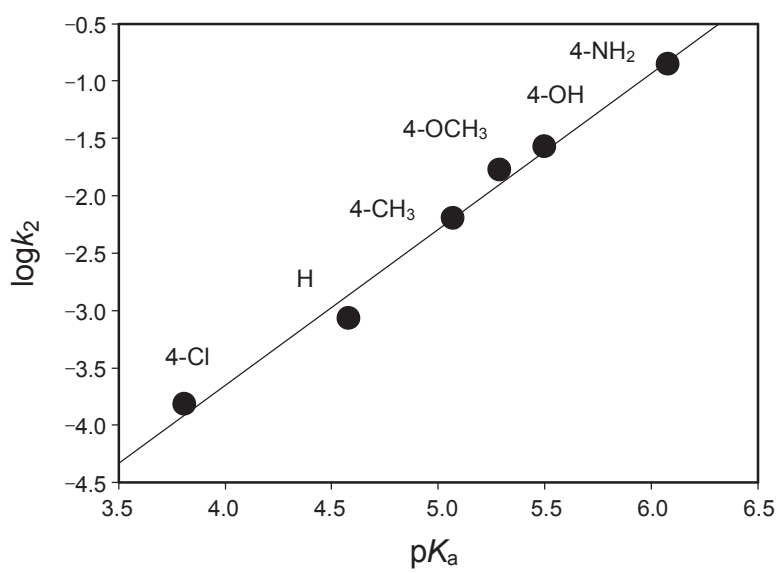

Figure 2. Typical Brönsted plot for the reaction of 4-chloro-7-nitrobenzofurazan with $4-\mathrm{X}$-anilines in $50 \% \mathrm{MeCN}-50 \% \mathrm{MeOH}$ solvents at $25{ }^{\circ} \mathrm{C}\left(\beta_{\text {nuc }}=1.36, \mathrm{r}=0.988\right)$.

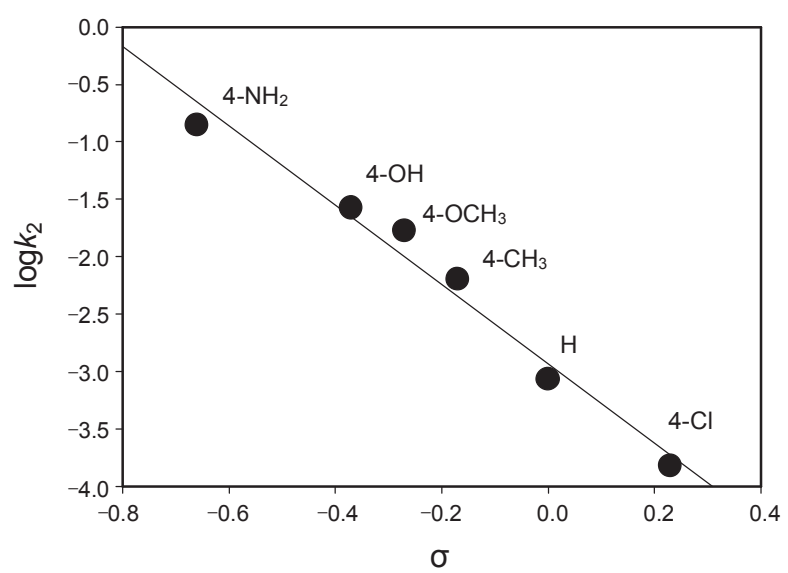

Figure 3. Typical Hammett plot for the reaction of 4-chloro-7-nitrobenzofurazan with $4-\mathrm{X}$-anilines in $50 \% \mathrm{MeCN}-50 \% \mathrm{MeOH}$ solvents at $25^{\circ} \mathrm{C}\left(\rho_{\mathrm{N}}=-3.45, \mathrm{r}=0.974\right)$.

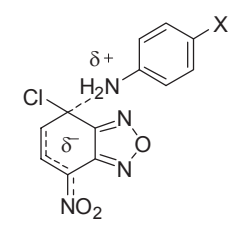

4

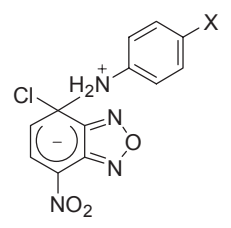

Scheme 1. Transition state (1) and Meisenheimer complex (2)

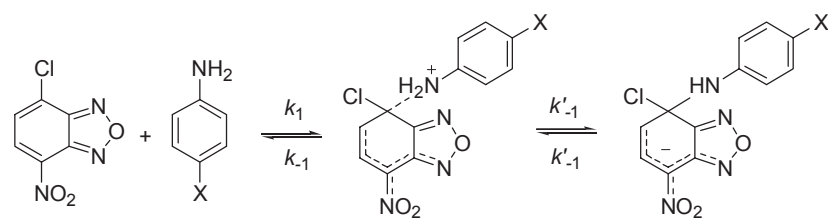

$\mathrm{X}=\mathrm{NH}_{2}, \mathrm{OH}, \mathrm{OCH}_{3}, \mathrm{CH}_{3}, \mathrm{H}, \mathrm{Cl}$
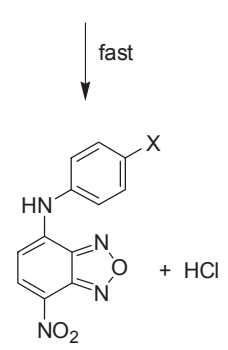

Scheme 2

ring in the TS 4 for formation of a zwitterionic intermediate $\sigma$ complex 5. The zwitterionic intermediate (Meisenheimer $\sigma$ complex) is stabilized through declocalization of negative charge by resonance, as shown in Scheme 1.

The large negative $\rho_{\mathrm{N}}$ and large positive $\beta_{\text {nuc }}$ values are in keeping with the traditional interpretation of nucleophilic aromatic substitution by amines, and this behavior accords well with the $\mathrm{S}_{\mathrm{N}} \mathrm{Ar}$-Ad.E mechanism shown in Scheme 2, where

Table 3. Additional rate constants $\left(\mathrm{M}^{-1} \mathrm{~s}^{-1}\right)$ for the reaction of 4-chloro- 7-nitrobenzofurazan with 4-X-anilines in $\mathrm{MeCN}-\mathrm{MeOH}$ mixtures at various temperatures and enthalpies $\left(\mathrm{kJ} \cdot \mathrm{mol}^{-1}\right)$ and entropies $\left(\mathrm{J} \cdot \mathrm{K}^{-1} \cdot \mathrm{mol}^{-1}\right)$ of activation

\begin{tabular}{|c|c|c|c|c|c|c|}
\hline & $\mathrm{p} K_{\mathrm{a}}$ & Solvent (v/v) & $\mathrm{t}\left({ }^{\mathrm{o}} \mathrm{C}\right)$ & $k_{2} \times 10^{3}\left(\mathrm{M}^{-1} \mathrm{~s}^{-1}\right)$ & $\Delta H^{\ddagger}\left(\mathrm{kJ} \cdot \mathrm{mol}^{-1}\right)$ & $-\Delta S^{\neq}\left(\mathrm{J} \cdot \mathrm{K}^{-1} \cdot \mathrm{mol}^{-1}\right)$ \\
\hline \multirow[t]{3}{*}{$4-\mathrm{Cl}$} & 3.81 & $\mathrm{MeOH}$ & $25^{\circ} \mathrm{C}$ & 0.723 & 19.3 & 241 \\
\hline & & & $35{ }^{\circ} \mathrm{C}$ & 0.900 & & \\
\hline & & & $45^{\circ} \mathrm{C}$ & 1.26 & & \\
\hline \multirow[t]{6}{*}{$\mathrm{H}$} & 4.58 & $\mathrm{MeOH}$ & $25^{\circ} \mathrm{C}$ & 2.67 & 42.3 & 152 \\
\hline & & & $35{ }^{\circ} \mathrm{C}$ & 4.51 & & \\
\hline & & & $45^{\circ} \mathrm{C}$ & 8.36 & & \\
\hline & & $50 \% \mathrm{MeCN}-50 \% \mathrm{MeOH}$ & $25^{\circ} \mathrm{C}$ & 0.851 & 36.9 & 180 \\
\hline & & & $35^{\circ} \mathrm{C}$ & 1.32 & & \\
\hline & & & $45^{\circ} \mathrm{C}$ & 2.32 & & \\
\hline \multirow[t]{6}{*}{$4-\mathrm{CH}_{3}$} & 5.07 & $50 \% \mathrm{MeCN}-50 \% \mathrm{MeOH}$ & $25{ }^{\circ} \mathrm{C}$ & 6.35 & 38.2 & 159 \\
\hline & & & $35^{\circ} \mathrm{C}$ & 9.90 & & \\
\hline & & & $45^{\circ} \mathrm{C}$ & 17.9 & & \\
\hline & & $\mathrm{MeCN}$ & $25{ }^{\circ} \mathrm{C}$ & 0.351 & 41.2 & 172 \\
\hline & & & $35^{\circ} \mathrm{C}$ & 0.820 & & \\
\hline & & & $45^{\circ} \mathrm{C}$ & 1.06 & & \\
\hline \multirow[t]{3}{*}{$4-\mathrm{OCH}_{3}$} & 5.29 & $\mathrm{MeCN}$ & $25^{\circ} \mathrm{C}$ & 1.59 & 44.4 & 150 \\
\hline & & & $35^{\circ} \mathrm{C}$ & 2.78 & & \\
\hline & & & $45^{\circ} \mathrm{C}$ & 5.24 & & \\
\hline
\end{tabular}


rate-limiting formation of the intermediate $\sigma$ complex is followed by fast expulsion of the chloride leaving group. ${ }^{2(a), 6,7,9,24}$ This indicates that deprotonation of complex $\mathbf{5}$ to give conjugate base $\mathbf{6}$ as well as subsequent re-aromatization of these species is a fast process relative to the nucleophilic addition step. ${ }^{9,24}$ The reactions of NBF-Cl with 4-X-subsiututed anilines have also been performed at $25.0,35.0$, and $45^{\circ} \mathrm{C}$ to determine activation parameters. The $\Delta H^{\star}$ and $\Delta S^{\star}$ values determined in the present system are summarized in Table 3. Such large negative $\Delta S^{\ddagger}$ values and small positive $\Delta H^{*}$ values suggest that the reaction takes place through a typical rate-determining nucleophilic addition in the present study. ${ }^{28,29}$

Single electron transfer (SET) pathway. The $\beta_{\text {nuc }}$ values are close to or greater than unity for various nucleophilic aromatic substitution reactions. The large $\beta_{\text {nuc }}$ values show greater sensitivity to substituent changes on the reaction at hand relative to the reference ionization equilibrium, ${ }^{9,1(a), 30}$ or in the case of $\mathrm{S}_{\mathrm{N}} 2$ reactions in terms of the advent of a SET pathway, where full electronic transfer occurs prior to the coupling of electrophilic and nucleophilic partners. ${ }^{3-5}$ The high $\beta_{\text {nuc }}$ values associated with the present reactions may be a reflection of a SET

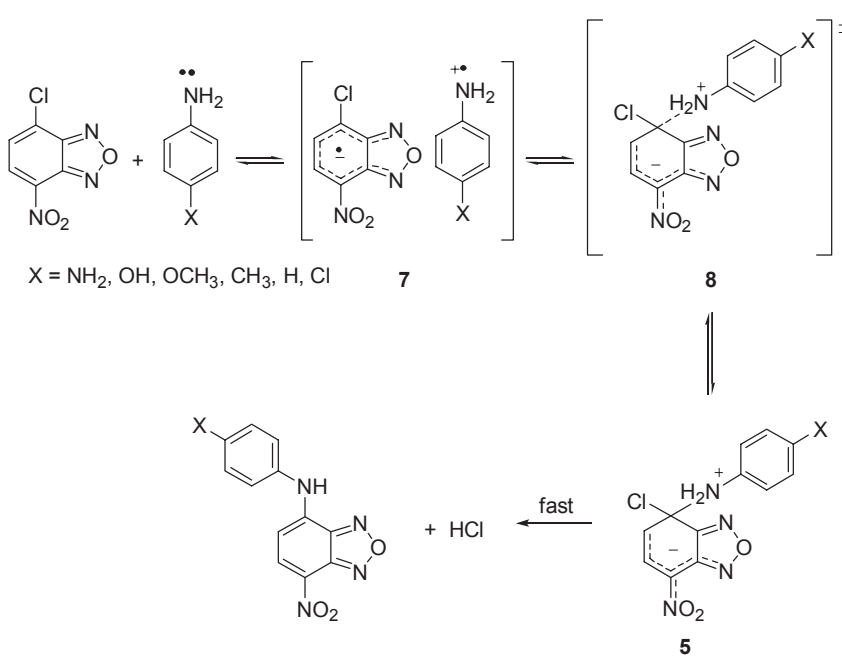

Scheme 3

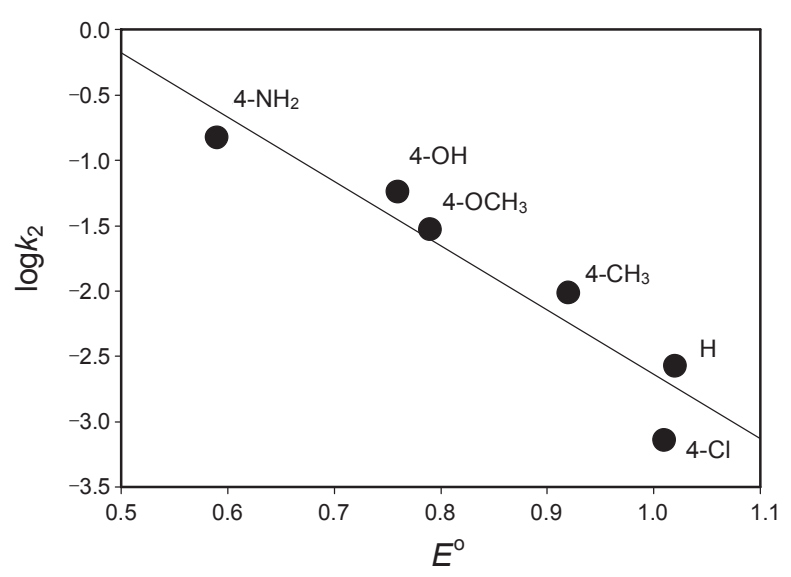

Figure 4. The influence of the reduction potential $E^{\circ}$ of anilines on the rates of reaction of 4-chloro-7-nitrobenzofurazan with 4-X-anilines in $\mathrm{MeOH}$ solvents at $25^{\circ} \mathrm{C}(\mathrm{r}=0.899)$. pathway, as described in Scheme 3. ${ }^{9}$ As in Scheme 3, one of the electrons of the lone pair in aniline (donor) is transferred to the nitrobenzofurazan acceptor moiety (7), and subsequent coupling between the resulting cation and the anion radicals within the solvent cage takes place. The transition state for the coupling reaction might be structure $\mathbf{8}$, and $\sigma$-complex intermediate 5 will be formed as a result.

One electron reduction potentials $E^{0}$ of $4-\mathrm{X}$-anilines in aqueous solutions were measured by Jonsson et al. ${ }^{30}$ Both the $E_{\mathrm{o}}$ and $\sigma_{\mathrm{p}}^{+}$, and $\mathrm{p} K_{\mathrm{a}}$ and $\sigma_{\mathrm{p}}^{+}$, plots show good linearity. ${ }^{30(\mathrm{a})}$ This indicates that the $\beta_{\text {nuc }}$ values are associated with one electron reduction (or oxidation potential), $E^{o}$. Plots of $\log k_{2}$ against $E^{o}$ values of 4-substituted anilines show a good linear relationship, as indicated in Figure 4. These results are clearly consistent with the SET pathway, as shown in Scheme 3.

\section{Conclusions}

A nucleophilic substitution reaction of 4-chloro-7-nitrobenzofurazan with anilines in $\mathrm{MeOH}-\mathrm{MeCN}$ mixtures was conducted. Based on the higher $\beta_{\text {nuc }}$ values $(1.0$ - 1.6) of the reaction and a good correlation of the rate constants with the reduction potentials of the aniline nucleophiles, the reaction was initiated by a single electron transfer (SET) mechanism, where one of the electrons in aniline is transferred to nitrobenzofurazan. After this step, the reaction of the present nitrobenzofurazan, which is an electrophilic benzenoide system such as 2,4,6-trinitochlorobenzene, proceeds through a transition state similar to the normal $\mathrm{S}_{\mathrm{N}} \mathrm{Ar}-\mathrm{Ad}$.E pathway.

\section{Experimental Section}

Materials. The 4-chloro-7-nitrobenzofurazan (Aldrich-GR), aniline (Aldrich-GR), $p$-anisidine (Aldrich-GR), $p$-chloroaniline (Aldrich-GR), and $p$-toludine (Aldrich-GR) were used commercial grade $(>98 \%)$. Merck HPLC grade $(<0.1 \%$ water $)$ methanol and acetonitrile were used without further purification.

Kinetics. Rates were measured conductimetrically at least in duplicate as in previous work. ${ }^{21,22,24}$

Product analysis. Anilinium salts were liberated quantitatively and identified as one of the reaction products by comparison of the UV-vis spectra after the completion of the reaction with those of authentic samples under same reaction conditions. For example, $\varepsilon=18992 \mathrm{M}^{-1} \mathrm{~cm}^{-1}$ at $476 \mathrm{~nm}$ for anilinium salt $\left(\mathrm{X}=\mathrm{OCH}_{3}\right)$. And also the products identified by ${ }^{1} \mathrm{H}$ NMR spectrum (Bruker $300 \mathrm{Mhz}$ ).

\section{References}

1. Wu, Z.; Glaser, R. J. Am. Chem. Soc. 2004, 126, 10632.

2. (a) Miller, J. Aromatic Nucleophilic Substitution Reaction; Elsevier: London, 1968. (b) Ross, S. D. Prog. Phys. Org. Chem. 1963, 1,31 .

3. Bordwell, F. G.; Branca, J. C.; Cripe, T. A. Isr. J. Chem. 1985, 26, 357.

4. Bordwell, F. G.; Clemens, A. H. J. Org. Chem. 1981, 46, 1037.

5. Bordwell, F. G.; Hugues, D. L. J. Am. Chem. Soc. 1986, 108, 5991.

6. Terrier, F. Aromatic Nucleophilic Substitution Reaction; VCH publisher: New York, 1991, Chapers 1 and 2. 
7. Bernasconi, C. F. MTP Int. Rev. Sci. Org. Chem. Ser. 1 1973, $3,33$.

8. (a) Jenks, W. P. In Nucleophilicity; Harris, J. M., Mc Manus, S. P., Eds.; Advances in Chemistry Series 215, American Chemical Society: Washington, DC, 1987; p 155.

9. Terrier, F.; Mokhtari, M.; Goumony, R.; Hallé, J.-C.; Buncel, E. Org. Biomol. Chem. 2003, 1, 1757.

10. (a) Lee, I. Chem. Soc. Rev. 1990, 19, 317. (b) Lee, I. Adv. Phy. Org. Chem. 1992, 27, 57 .

11. (a) Williams, A. Chem. Soc. Rev. 1994, 93. (b) Page, A.; Williams, A. In Organic and Bio-organic Mechanisms; Longman: Harlow, Chapter 3. (c) Kresge, A. J. Chem. Soc. Rev. 1973, 2, 475.

12. (a) Bordwell, F. G.; Hughes, D. L. J. Am. Chem. Soc. 1986, 108, 5991. (b) Moutiers, G.; Guével, E. L.; Cannes, C.; Terrier, F.; Buncel, E. Eur. J. Org. Chem. 2001, 3279. (c) Sung, R. Y.; Choi, H.; Lee, J. P.; Park, J. K.; Yang, K.; Koo, I. S. Bull. Korean Chem. Soc. 2009, 30, 1579.

13. (a) Bordwell, F. G.; Boyle, W. J. J. Am. Chem. Soc. 1972, 94 , 3907. (b) Bordwell, F. G.; Hautala, J. A. J. Org. Chem. 1978, 43, 3116.

14. Jenks, W. P.; Haber, M. T.; Herschlag, D.; Nazaretian, K. L. J. Am. Chem. Soc. 1986, 108, 479.

15. Bernasconi, C. F. Adv. Phy. Org. Chem. 1992, 27, 119.

16. Lee, H. W.; Lee, I. J. Korean Chem. Soc. 1978, 22, 221.

17. (a) Koniglio, B. O. et al. J. Chem. Soc. 1966, 152. (b) Parker, A. J. Ibid 1961, 4398

18. (a) Kingsbury, C. A. J. Org. Chem. 1964, 29, 3262. (b) Ballestreri, F. P. et al. J. Org. Chem. 1977, 42, 1415.

19. Banjoko, O.; Babatunde, I. A. Tetrahedron 2004, 60, 4645.
20. Mancini, P. M.; Fortunato, G. G.; Votlero, L. R. J. Phys. Org. Chem. 2004, 17, 138.

21. Koh, H. J.; Han, K. L.; Lee, H. W.; Lee, I. J. Org. Chem.1998, 63, 9834.

22. Kang, D. H.; Koo, I. S.; Lee, J. G.; Lee, I. J. Korean Chem. Soc. $1985,29,565$.

23. Koo, I. S. et al. Unpublished results.

24. Hwang, J.; Yang, K.; Koo, I. S.; Sung, D. S.; Lee, I. Bull. Korean Chem. Soc. 2006, 27,733 .

25. (a) Ritchie, C. D. In Solute-Solvent Interactions; Coetzee, J. F., Ritchie, C. D., Eds.; Marcel Dekker: New York, 1969; Chapter 4. (b) Coetzee, J. F. Progress in Physical Organic Chemistry; Streitwieser, A., Jr., Taft, R. W., Eds.; Wiley; New York, 1967; Vol. 4, pp 54-92. (c) Spillane, W. J.; Hogan, G.; McGrath, P.; King, J.; Brack, C. J. Chem. Soc., Perkin Trans. 2 1996, 2099. (d) Lee, I.; Kim, C. K.; Han, I. S.; Lee, H. W.; Kim, W. K.; Kim, Y. B. J. Phys. Chem. B 1999, 103, 7302 .

26. Ryan, J. J.; Humffray, A. A. J. Chem. Soc. B 1967, 1300. (Introduction ref. 2 추가)

27. Sung, R. Y.; Choi, H.; Lee, J. P.; Park, J. K.; Koo, I. S. Bull. Korean Chem. Soc. 2009, 30, 1579.

28. Shin, G.-C.; Hwang, J.; Yang, K.; Koo, I. S.; Lee, I. Bull. Korean Chem. Soc. 2005, 26, 1981.

29. Bernasconi, C. F.; Stronach, M. W. J. Am. Chem. Soc. 1993, 115, 1341.

30. (a) Jonsson, M.; Lind, J.; Ericksen, T. E.; Merényi, G. J. Am. Chem. Soc. 1994, 116, 1423. (b) Bacon, J.; Adams, R. N. J. Am. Chem. Soc. 1968, 90, 6596. 